Dra. Daniela Musicco Nombela

Directora de Comunicación y Hombre

@ daniela.musicco@ufv.es_iD 0000-0001-7325-9978

\title{
Rigor y sensibilidad en la era de la posverdad
}

\section{Rigor and sensitivity in the post-truth era}

¿Cuál es el sentido del rigor y la sensibilidad en la Comunicación contemporánea?

Cuando emprendimos la edición de este nuevo número de la revista nos propusimos hacer un llamamiento para conocer el uso del rigor y la sensibilidad en la Comunicación en relación con diferentes disciplinas, quisimos conocer la frontera entre profesión, disciplina y humanidad, visión y mirada. Abordamos el estudio del ejercicio del rigor y la sensibilidad en el campo de la Comunicación con el trasfondo de la llamada era de la posverdad.

Estábamos interesados en el análisis de la aplicación del rigor y la sensibilidad en las profesiones que deben o deberían comunicar poniéndose o estando en el lugar del otro y de las disciplinas que deben hacer uso en su estudio y conocimiento de la realidad, del rigor, producto de la razón y de la sensibilidad, para salir al encuentro de la verdad.

Hemos hecho un llamamiento para recoger artículos que traten estos temas en el Periodismo, la Publicidad, la Comunicación Empresarial, el Marketing, la Pedagogía, la Psicología, la Filología, la Filosofía y la Teología.

Conscientes de que vivimos en un mundo abarrotado de imágenes, de información, de comunicación, conocemos la anestesia sensorial y de pensamiento que invade la existencia contemporánea y que hace posible mirar despreocupados un desfile de moda por las calles de La Habana, mientras Cuba esconde su pobreza a cambio de un plato de arroz. Sabemos que podemos llorar la historia de Nadia, sin preguntarnos si es verdad, sin corroborar nada, simplemente seducidos por la mirada del share.

Escuchamos el horror de un laudado «yo estuve ahí» de los enviados especiales, o el «yo oí el disparo, esquivé la bomba»... de los corresponsales de guerra, supervivientes humanos 
de una derrota inhumana y seguimos haciendo nuestra vida sin cambiar nada.

Recibimos las imágenes y sonidos de lugares que siempre nos resultan muy lejanos; los reporteros nos las envían, nos las traen y después, de vuelta a casa, como cazadores con sus triunfos, cuelgan sus fotografías y crónicas en las web, en los blog o en las paredes de confortables salones.

Conocemos que hay miles de hambrientos y de muertos, de los que nunca cogieron un avión para contar su propia historia, de los que no compraron un billete de ida y vuelta, ni de primera, ni de turista, ni de tren, ni de metro, para sobrevivir, de los que no tuvieron la oportunidad de explicar cómo pensaban o cómo hubiesen querido que fuera su futuro.

Son los cuerpos abatidos sobre los duros asfaltos, asesinados sin disculpa por los terroristas, mudos para siempre, en el silencio; son los mismos asfaltos que ahora unos hombres perdonados, y ellos sí, con vida, los vuelven a caminar; son esos hombres que pasan delante de las cámaras y lanzan unas casi imperceptibles miradas esquivas, que nos cuestionan, pero no nos preguntamos nada.

Es la imagen, y no el niño sirio ya olvidado, de la playa de Bodrum en Turquía. ¿Era cierta esa imagen? El breve escalofrío de un escándalo que silencia a miles de otros niños, abandonados sobre unas conciencias tan adormecidas por una sensibilidad que sólo responde al mando a distancia, negados como hombres por una falta de rigor vital que nos arrastra más allá del mar adentro.

Sin querer desprestigiar el mérito y el valor (muchos pierden sus vidas), de quienes cuentan y comunican el dolor, subrayamos la enorme brecha que divide los dos mundos: los que trabajan sobre las miserias de esta tierra, las comunican, las venden, las compran, las emiten, las retwittean... de los que las sufren realmente. ¿Cómo ejercemos nuestras profesiones, con qué rigor y sensibilidad? ¿Deberíamos retomar el camino de la educación del rigor y la sensibilidad?

Asalta la duda sobre qué mueve nuestro entorno comunicativo actual: ¿es verdad lo que enseñamos o es una construcción hecha ex profeso para ganar audiencia, likes o clics?

Arrastrados en un flujo constante de comunicación, las fake news aparecen como falsos troncos, espejismos de información, que precipitan inexorablemente en el vacío abismal de esta inundación que nos ahoga en la llamada era de la posverdad. Nos aleja de la implicación, de la voluntad de descubrir la verdad, de conocer realmente con rigor, de sentir, nos ciega y nos aturde y nos devuelve visiones enajenadas.

Para tratar de comprender qué está moviendo estas miradas indiferentes, hemos abordado el tema del Rigor y Sensibilidad en este nuevo número de Comunicación y Hombre, hemos pedido abrir un diálogo entre la Comunicación y diversas disciplinas para lograr encontrar puntos de encuentro de una nueva búsqueda de ese rigor y sensibilidad.

El primer campo de exploración que abordamos en este número 15 es el de la Comunicación oral en relación con la traducción y la búsqueda en la Etimología o la Filología de aquellos matices sensibles capaces de comunicar adecuadamente y con rigor. Tal y como explica la Dra. María Mercedes Eurrutia Cavero, de la Universidad de Alicante en su texto "Literatura y traducción: problemas que plantea y situación actual" (1996):

Es necesario que el traductor posea una sensibilidad especial que le permita percibir las menores pulsaciones de ritmo, esa cadencia secreta que revela el espíritu interno 
de la obra y al mismo tiempo, realice un análisis detallado para captar la relación que existe entre las ideas más sutiles.

En este área de estudio se mueve el artículo que hemos incluido en este número y que ha llegado de la Universidad de Teherán del autor Dr. Afsaneh Pourmazaheri y la Dra. Sharareh Chavoshian, "Sensibilidad y rigor en la traducción: la autonimia como solución apelativa", sobre los antiguos viajeros franceses que en el S.XIX viajaron a Persia; explica el texto con qué rigor y sensibilidad pudieron nombrar y comunicar aquellas cosas que vieron y no existían en su país de origen, ni en su idioma, en su lenguaje.

Siempre en la búsqueda contemporánea del rigor y la sensibilidad en la Psicología encontramos trabajos como el artículo que hemos recibido de la dra. Lavinia Barone desde la Universidad de Pavia: "Enseñar la disciplina sensible a los padres. Aprender participando" ilustra sobre cómo a partir de la teoría del apego, el desarrollo de un niño depende en gran medida de la sensibilidad con la que se desarrollan los intercambios comunicativos cotidianos, sin perder la disciplina: «disciplina sensible» que busca «conjugar una actitud sensible con el respeto y la firmeza de las reglas disciplinarias». Siguiendo a otra investigadora, la Dra. Francesca Lionetti, Doctora en Psicología también de la Universidad de Pavia, actualmente investigadora post-doctoral en la Universidad Queen Mary en Londres, el artículo de la Dra Barone es una nueva aportación sobre la importancia de la disciplina sensible:

demostrar que incluso aspectos convencionales cotidianos y "simples", como conjugar sensibilidad y afecto con la disciplina y el rigor, pueden convertirse en instrumentos refinados y estructurados de gran ayuda en la tarea antigua, pero siempre desafiante, de ejercer de padre con atención y afecto, pero sin renunciar a su papel educativo y disciplinario.

En estos trabajos de investigación se encuentra el eco también del desarrollo de la inteligencia sensible y de las personas de alta sensibilidad, PAS, un área de investigación científica que ha impulsado el reciente I Congreso Internacional sobre Alta Sensibilidad celebrado en Valencia en mayo de 2018.

En Pedagogía, en Psicología y Neurología están aportando nuevos horizontes la investigación rigurosa de la idea de la sensibilidad y la inteligencia.

Por todo esto hemos recibido con mucho interés artículos como el de la Dra. María José Gato Bermúdez de la Universidad San Pablo CEU, sobre Pedagogía, exigencia y sensibilidad en la educación; o el artículo sobre el uso el de los TED talk, que, bajo el título "Del rigor a la retórica emocional", analiza este instrumento comunicativo, gracias al trabajo del Dr. Francisco López-Cantos de la Universidad Jaume I.

La inteligencia y la sensibilidad ha sido objeto de estudio también en la Filosofía y la Teología. Un ejemplo reciente es el trabajo del Dr. Juan José García, de la Universidad de Navarra, sobre "Inteligencia Sentiente" (2006) siguiendo al filósofo y teólogo español, el Dr. Xavier Zubiri y su investigación sobre la "Inteligencia Sentiente: Inteligencia y Razón" (1983). Del ámbito de la Teología y su comunicación a través de los mass media, contamos en este número con el artículo del Dr. Álvaro Mateos de la Universidad Pontificia de Salamanca sobre "El papel de un teólogo en los medios: rigor y sensibilidad en Olegario González de Cardedal".

El rigor y la sensibilidad han interesado por tanto a tan diferentes disciplinas como la 
Psicología, la Teología, la Filología e incluso la Ingeniería donde, por ejemplo, encontramos el trabajo del ingeniero español Dr. Juan José Arenas de Pablo, de la Universidad de Cantabria, quien pronunció una conferencia cuyo título era precisamente "El rigor y la sensibilidad en la Ingeniería" (2003) y posteriormente publicó el artículo "Rigor y sensibilidad: trabajo de ingenieros" (2004), en el que muestra un aspecto de la Ingeniería que a menudo se deja al margen del concepto de las propias obras. Este prolijo autor de numerosas obras y de multitud de artículos y escritos hasta su fallecimiento en 2017, abordó el tema de la sensibilidad uniéndolo a una necesidad humana en la construcción rigurosa de obras de ingeniería.

El campo de la Medicina y la comunicación a los pacientes y familiares es un área de investigación y trabajo cada vez más interesada a los términos del rigor y la sensibilidad; así lo demuestra la celebración de un Congreso organizado por la Sociedad de Oncología Médica: "Rigor, sensibilidad y respeto: claves para informar sobre el cáncer" (2006).

Otro ejemplo en esta dirección es el proyecto del Programa de Humanidades Médicas de la Universidad Francisco de Vitoria, cuyo trabajo, realizado desde hace años, se centra en una comprensión global del paciente, cuidando el aprendizaje a través del rigor y el uso de la sensibilidad en temas como la comunicación de la enfermedad a través de prácticas específicas. El Programa de Pacientes Simulados, que nació para dar respuesta a una necesidad docente, es un buen ejemplo, y así lo explica su coordinador, el Dr. Roger Ruiz Moral en el artículo "Medicina de la UFV, pionera y centrada en la persona con el Programa Pacientes Simulados" (2014): «El programa surge para trabajar habilidades de comunicación entre el médico y el paciente».

Finalmente el campo de la Comunicación en Publicidad, Cine, Marketing o Periodismo, en los medios tradicionales y en redes sociales, aporta numerosos trabajos en los que se aúna esta búsqueda del rigor y la sensibilidad.

En una campaña reciente de Publicidad para la marca Ruavieja, Tenemos que vernos más (noviembre 2018), de la agencia Leo Burnett, se encuentra un claro ejemplo de la búsqueda publicitaria del rigor y la sensibilidad, tratando de unir unos cálculos de probabilidades matemáticas con las vidas afectivas y encuentros emocionales de un grupo de personas estudiados para la campaña; otro ejemplo reciente en el campo de la Comunicación llega desde el cine con aportaciones como la película Campeones (2018) en la que el trabajo realizado ha tratado de unir el rigor del tratamiento de un tema como la inclusión y respeto hacia los discapacitados con la sensibilidad del trabajo realizado con disminuidos psíquicos reales. Ambos ejemplos han estado presentes en la "III Jornada de Comunicación" en la Universidad Francisco de Vitoria, organizada por la propia revista, con la colaboración de la Facultad de Comunicación, del Departamento de Comunicación UFV, del Instituto de Innovación y de la Cátedra Santander de Responsabilidad Social, bajo el título de Rigor y Sensibilidad en la Comunicación (diciembre 2018) para dar a conocer el contenido de este número de la revista y para crear un debate entre diferentes profesionales en ejercicio y construir un diálogo teórico con investigadores académicos y estudiantes. La presencia de una mesa sobre periodismo de investigación y su acercamiento al tema del rigor y la sensibilidad ha aportado también otro de los enfoques importantes del tema propuesto en este número: la mirada sensible y rigurosa sobre la realidad por parte de la prensa.

El rigor y la sensibilidad aparecen como un antídoto a la proliferación de las fake news, «un fenómeno nuevo con siglos de historia» como apunta el doctor en Ciencias de la Información de la 
Universidad Complutense de Madrid, Dr. José Manuel Burgueño (2018); a las fake news se refiere como a un arma de intoxicación masiva. En la versión española del Digital News Report 2018 de Reuters Institute de la Universidad de Oxford, los doctores Avelino Amoedo, Samuel Negredo y Alfonso Vara-Miguel, de la Universidad de Navarra indican que el $84 \%$ de los entrevistados piensa que: «los periodistas y los medios son quienes deben combatir la proliferación de las fake news". Las fake news son también el contenido del artículo en este número de Comunicación y Hombre del Dr. Pedro Silverio Moreno, de la UNED, cuyo título es "El rigor informativo en la era de la posverdad: la amenaza de las fake news en las redes sociales".

En este número no han faltado investigaciones muy interesantes sobre otras cuestiones como videojuegos y "Una aproximación ética al terror" del Dr. Ángel Agejas Esteban de la Universidad Francisco de Vitoria o "El rol del Producer en las agencias publicitarias" de los doctores Jorge Clemente Mediavilla y Ana Visiers Elizaincín de la Universidad Complutense de Madrid; siempre en el campo de la publicidad la Dra. Esther Martinez Pastor de la Universidad Rey Juan Carlos junto al Dr. Miguel Ángel Nicolás Ojeda de la Universidad de Murcia firman el artículo "Panorámica de las reclamaciones en publicidad y menores en Autocontrol (19982018)", que presenta un panorama general de todas las reclamaciones recogidas en los últimos veinte años; el artículo "Bilbo Bolsón o de cómo un hobbit nos enseñó las virtudes de la fe" del Dr. Rafael García Pavón de la Universidad de Anáhuac México, aporta una reflexión sobre el personaje de Tolkien y muestra cómo las elecciones vitales pueden favorecer la aparición de la verdad; la búsqueda de un marco de comunicación adecuado para hacer posible un diálogo entre razón y fe, ha sido el núcleo del artículo "¿Cómo pensar y hablar sobre Dios, hoy? Bases conceptuales para un diálogo renovado entre razón y fe" del Dr. Juan Jesús Álvarez Álvarez de la Universidad Francisco de Vitoria.

Finalmente deseamos destacar las tres reseñas sobre tres libros de publicación reciente: de la Dra Carmen Fragero es la reseña sobre The only story de Julian Patrick Barnes (2018); del Dr. Pablo Garrido sobre MMLB. Nosotros, los persuasores de Sergio Rodríguez (2018) y de Martín Rocha Originalidad e identidad personal: claves antropológicas frente a la masificación de Javier Barraca Mairal (2017). 